\title{
PENGARUH AKTIVASI SECARA KIMIA MENGGUNAKAN LARUTAN ASAM DAN BASA TERHADAP KARAKTERISTIK ZEOLIT ALAM
}

\section{THE EFFECT OF CHEMICAL ACTIVATION BY USING ACID AND BASE SOLUTION ON NATURAL ZEOLITE CHARACTERISTICS}

\author{
Muhammad Al Muttaqii ${ }^{1 *}$, David Candra Birawidha ${ }^{1}$, Kusno Isnugroho ${ }^{1}$, \\ Muhammad Amin'1, Yusup hendronursito' ${ }^{1}$, Amila Dini Istiqomah², \\ Diego Putra Dewangga² \\ ${ }^{1}$ Balai Penelitian Teknologi Mineral, Lembaga Ilmu Pengetahuan Indonesia \\ Tanjung Bintang-Lampung Selatan, 35361, Indonesia \\ 2Jurusan Teknik kimia, Fakultas Teknologi Industri, Institut Teknologi Sepuluh Nopember \\ Sukolilo, Surabaya, 60111, Indonesia \\ *Email: almuttaqiimuhammad@gmail.com
}

Diterima : 02-10-2019

Direvisi : 28-11-2019

Disetujui : 03-12-2019

\begin{abstract}
ABSTRAK
Zeolit alam merupakan batuan mineral yang banyak terdapat di Indonesia. Zeolit alam merupakan kristal alumino silikat yang memiliki banyak kegunaan dalam bidang industri, agrikultura, dan pengolahan air limbah. Salah satu proses untuk meningkatkan kualitas dari zeolit alam adalah melalui proses aktivasi. Tujuan penelitian ini adalah melihat pengaruh aktivasi secara kimia menggunakan larutan asam klorida dan natrium hidroksida sehingga mampu meningkatkan aktivitas dari zeolit alam tersebut. Aktivasi zeolit alam dilakukan secara kimia dengan menggunakan larutan $\mathrm{HCl}$ dan $\mathrm{NaOH}$ pada variasi konsentrasi 0.5 , $1,1.5,2$, 2.5 M. Selanjutnya zeolit tersebut dianalisa menggunakan XRD dan XRF. Hasil XRD menunjukkan fase utama dari zeolit alam adalah mordenite. Sedangkan hasil XRF menunjukkan senyawa silika $\left(\mathrm{SiO}_{2}\right)$ dengan perlakuan asam $(\mathrm{HCl})$ berada dikisaran $75-76 \%$ sedangkan dengan perlakuan basa $(\mathrm{NaOH})$ berada dikisaran $72-73 \%$. Proses perlakuan asam pada zeolit alam menyebabkan terjadinya penurunan kandungan $\mathrm{Ca}$ dan $\mathrm{Mg}$ pada zeolit.
\end{abstract}

Kata kunci : Aktivasi, $\mathrm{HCl}, \mathrm{NaOH}$, Silika, Zeolit alam

\section{ABSTRACT}

Natural zeolite is a mineral rocks which are common in Indonesia. Natural zeolite is a crystalline aluminosilicate which has been used in many fields of industry, agriculture, and waste water treatment. The activation process will be able to increase the activity of the natural zeolite. The activation of natural zeolite was done by using chloride acid ( $\mathrm{HCl}$ ) and sodium hydroxide ( $\mathrm{NaOH}$ ) solutions at various concentration of $0.5,1,1.5,2,2.5 \mathrm{M}$. The natural zeolites activation was analyzed by using XRD and $X R F$. Based on the XRD results, the main content of natural zeolite is mordenite. Based on the results of XRF showed silica $\left(\mathrm{SiO}_{2}\right)$ compounds with acid treatment $(\mathrm{HCl})$ in the range of $75-76 \%$, while those with base treatment ( $\mathrm{NaOH}$ ) were in the range of $72-73 \%$. The process of acid treatment in natural zeolites causes the decrease of $\mathrm{Ca}$ and $\mathrm{Mg}$ content in the natural zeolite.

Keywords : Activation, $\mathrm{HCL}, \mathrm{NaOH}$, Natural zeolite, Silica

266 Muhammad Al Muttaqii, David Candra Birawidha, Kusno Isnugroho, Muhammad Amin, Yusup hendronursito, Amila Dini Istiqomah, Diego Putra Dewangga Pengaruh Aktivasi Secara Kimia Menggunakan Larutan Asam dan Basa Terhadap Karakteristik Zeolit Alam 


\section{PENDAHULUAN}

7 eolit alam merupakan mineral yang terdiri dari Kristal alumino silikat. Struktur zeolit terdiri dari $\mathrm{AlO}_{4}$ dan $\mathrm{SiO}_{4}$. Rumus kimia zeolit secara empiris ditunjukkan sebagai berikut $\mathrm{M}_{\mathrm{x} / \mathrm{n}} \cdot\left[\left(\mathrm{AlO}_{2}\right)_{\mathrm{x}} \cdot\left(\mathrm{SiO}_{2}\right)_{\mathrm{y}}\right] \cdot \mathrm{wH}_{2} \mathrm{O}$, dimana notasi $\mathrm{M}$ adalah kation logam alkali atau alkali tanah, $\mathrm{x}, \mathrm{y}$, dan $\mathrm{w}$ adalah bilangan-bilangan tertentu sedangkan $\mathrm{n}$ adalah muatan dari ion logam (Bekkum, 1991).Zeolit juga mempunyai struktur mikroporous sehingga dapat menyediakan tempat yang besar untuk terjadinya reaksi serta memungkinkan reaksi dapat berlangsung pada tekanan yang lebih tinggi. Rasio Si/Al yang cukup tinggi pada zeolit menyebabkan zeolit bersifat hidrofobik organofilik yang akan mendukung proses difusi reaktan. Dimensi molekular zeolit juga menyebabkan zeolit selektif terhadap reaktan, produk, serta keadaan transisi. Zeolit alam terbentuk karena adanya perubahan alam (zeolitisasi) dari bahan vulkanik dan dapat digunakan secara langsung (Hamdan, 1992).

Aplikasi penggunaan zeolit sangat banyak seperti pada industri, agrikultura, dan pengolahan air limbah. Dalam bidang industri, zeolit digunakan sebagai adsorben, katalis, dan penghilang logam berat (Al Muttaqii, et al., 2019). Oleh karena itu upaya peningkatan potensi zeolit alam perlu dikembangkan dengan baik sehingga aplikasinya bisa lebih bervariasi untuk keperluan dalam bidang lingkungan, industri, dan pertanian. Hingga saat ini, zeolit alam terus diupayakan pemanfaatannya pada berbagai bidang. Zeolit alam dapat mengandung lebih dari 50 mineral yang berbeda (Gaydardjief, et al., 2001). Menurut Tsitsishvili, et al., (1992) berbagai jenis mineral zeolit yang umum terdapat di alam diantaranya mordenite, clinoptilolite, phillipsite, chabazite. Sedangkan menurut Demir, et al., (2002) clinoptilolite merupakan salah satu jenis mineral zeolit alam yang biasa digunakan untuk mengurangi logam berat dalam larutan.

Zeolit alam mempunyai cukup banyak pori yaitu sekitar $30 \%$ lebih dari volumenya dan banyak bercampur dengan materi pengotor (impurities) selain zeolit, oleh karena itu zeolit alam perlu diaktivasi dan dimodifikasi guna meningkatkan aktivitasnya. Melalui proses aktivasi, unsur pengotor dapat dihilangkan dan merubah rasio Si/Al. Proses aktivasi bisa dilakukan dengan cara pemanasan, penambahan asam maupun basa (Djaeni, et al., 2010).Aktivasi secara fisik dilakukan dengan cara pengecilan ukuran butir, pengayakan dan pemanasan pada suhu tinggi yang bertujuan untuk menghilangkan pengotor-pengotor organik, memperbesar ukuran pori dan memperluas permukaan. Proses aktivasi fisika dapat dilakukan dengan kalsinasi zeolit alam pada suhu $600{ }^{\circ} \mathrm{C}$. Aktivasi secara kimia dapat dilakukan dengan menggunakan larutan asam klorida $(\mathrm{HCl})$ atau asam sulfat $\left(\mathrm{H}_{2} \mathrm{SO}_{4}\right)$, maupun larutan natrium hidroksida $(\mathrm{NaOH})$ yang bertujuan untuk membersihkan permukaan pori, menghilangkan senyawa pengotor (Ambarwati, 2005). Menurut Suriawan dan Nindhia (2010), penambahan asam akan memperbesar porositas sehingga keatifan zeolit meningkat.

Pada penelitian ini akan dilakukan pengaruh aktivasi secara kimia menggunakan larutan asam klorida $(\mathrm{HCl})$ dan natrium hidroksida $(\mathrm{NaOH})$ agar sejumlah kelemahan dari zeolit alam dapat diatasi seperti mengandung banyak pengotor, komposisi yang beragam dan kristalinitasnya yang kurang baik.

\section{METODE PENELITIAN \\ Bahan}

Bahan yang digunakan dalam percobaan ini adalah zeolit alam yang berasal dari Bandung. Natrium hidroksida $(\mathrm{NaOH})$ dan asam klorida $(\mathrm{HCl})$ dari Merck.

\section{Preparasi Zeolit Alam}

Zeolit alam digerus dan diayak. Kemudian aquades ditambahkan kedalam zeolit yang telah diayak dan distirrer selama 24 jam pada suhu ruang. Zeolit yang telah direndam kemudian 
dioven pada suhu $110{ }^{\circ} \mathrm{C}$ hingga kering. Zeolit dikeluarkan dari oven untuk ditumbuk dan diayak.

\section{Aktivasi Zeolit Alam}

Sebanyak $13 \mathrm{gr}$ zeolit alam ditambahkan dengan $100 \mathrm{~mL}$ larutan asam/basa sesuai variable konsentrasi yang telah ditentukan yaitu $0.5,1$, 1.5, 2, dan $2.5 \mathrm{M}$. Kemudian distirrer selama 2 jam. Zeolit alam kemudian dibilas dengan aquades, disaring dan dioven pada suhu $110{ }^{\circ} \mathrm{C}$ hingga kering. Zeolit alam kemudian dikalsinasi selama 3 jam pada suhu $500{ }^{\circ} \mathrm{C}$.

\section{Karakterisasi Zeolit Alam}

Zeolit alam yang telah diaktivasi kemudian dianalisa mengunakan XRD (PANalytical X'Pert ${ }^{3}$ ) untuk melihat struktur kristalinitas dari zeolit alam. Sedangkan komposisi kimia zeolit alam yang telah diaktivasi dianalisa menggunakan XRF (Epsilon $\left.{ }^{3 \mathrm{XLE}}\right)$.

\section{HASIL DAN PEMBAHASAN}

\section{Hasil Pengujian XRD}

Hasil pengujian XRD zeolit alam yang diaktivasi asam $(\mathrm{HCl})$ dan basa $(\mathrm{NaOH})$ ditunjukkan pada Gambar 1 dan Gambar 2. Gambar 1 menunjukkan, komposisi mineral zeolit alam yang diaktivasi asam klorida $(\mathrm{HCl})$ terdiri dari Mordenite $\left(\mathrm{Al}_{2} \mathrm{Si}_{10} \mathrm{O}_{24} .7 \mathrm{H}_{2} \mathrm{O}\right)$, Cristobalite $\left(\mathrm{SiO}_{2}\right)$, Trydimite $\left(\mathrm{SiO}_{2}\right)$, dan Moganite $\left(\mathrm{SiO}_{2}\right)$. Sedangkan pada Gambar 2 menunjukkan komposisi mineral zeolit alam yang diaktivasi dengan natrium hidroksida terdiri dari Mordenite $\left(\mathrm{Al}_{2} \mathrm{Si}_{10} \mathrm{O}_{24} .7 \mathrm{H}_{2} \mathrm{O}\right)$, Quartz $\left(\mathrm{SiO}_{2}\right)$, Cristobalite $\left(\mathrm{SiO}_{2}\right)$, dan Sanidine $\left(\mathrm{K}\left(\mathrm{AlSi}_{3} \mathrm{O}_{8}\right)\right)$.

Berdasarkan hasil pengujian XRD dengan aktivasi kimia (asam/basa) akan diperoleh struktur mineral modernit. Modernit merupakan kelompok zeolit yang termasuk ke dalam zeolit mikropori dengan struktur kristal orthorombik dengan saluran-saluran terbuka yang memungkinkan air dan ion-ion berukuran besar keluar dan masuk melalui saluran tersebut. Berdasarkan sifatnya ini, zeolit bisa digunakan sebagai media adsorben. Sifat zeolit ini sama halnya dengan zeolit alam malang, zeolit alam gunung kidul karena memiliki struktur mordenit (Mazloomi, et al., 2015).

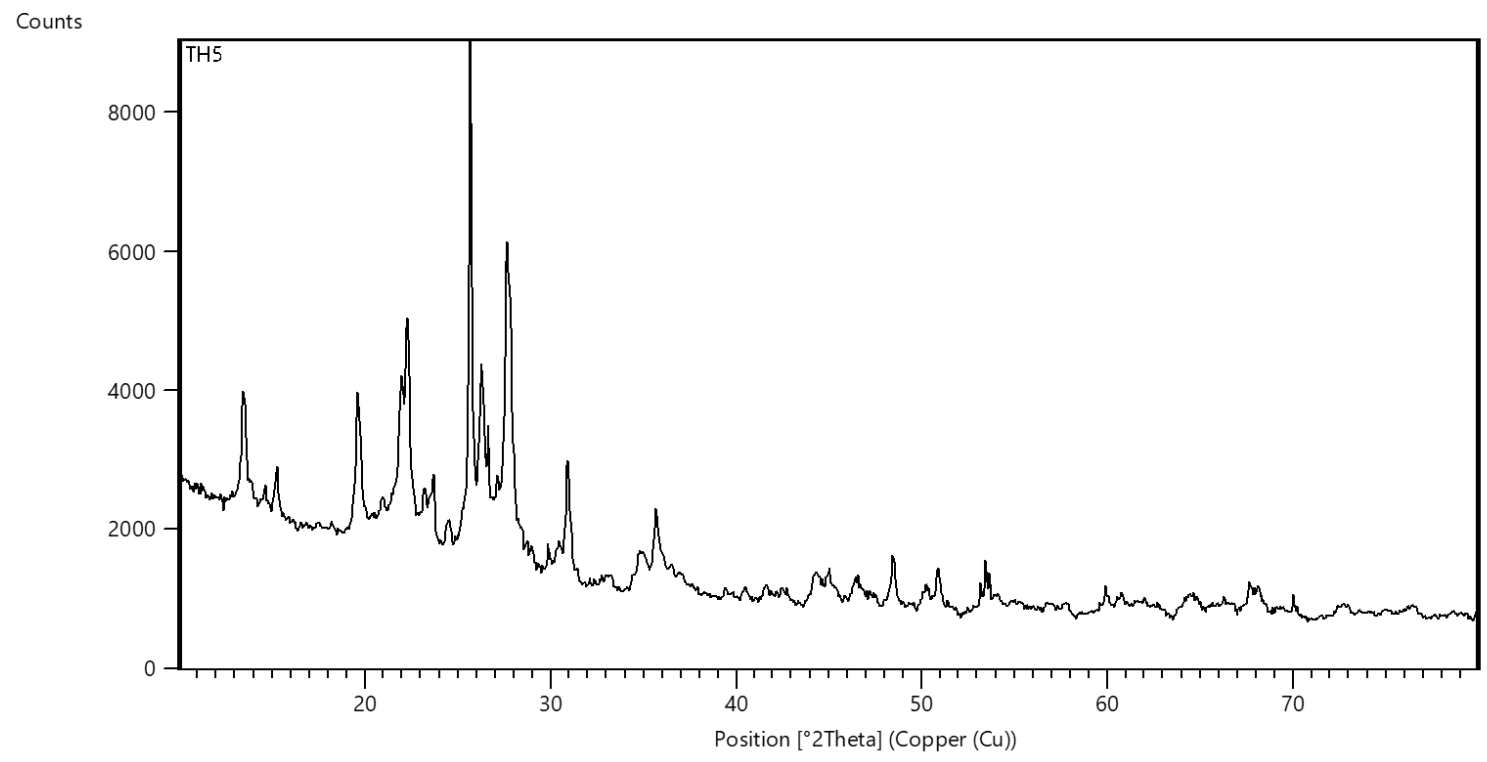

Gambar 1. Difraktogram zeolit alam yang diaktivasi asam klorida $(\mathrm{HCl})$ 


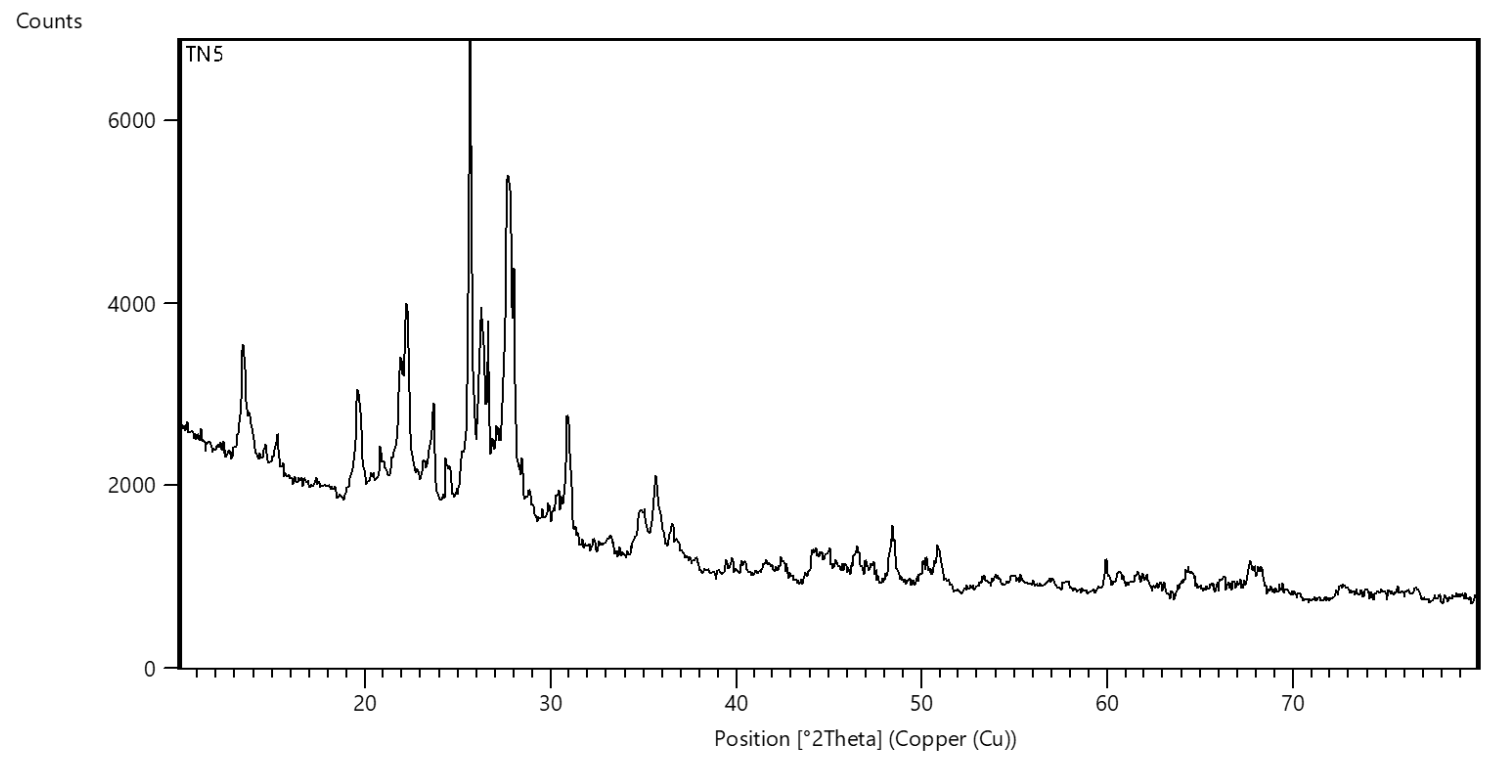

Gambar 2. Difraktogram zeolit alam yang diaktivasi basa $(\mathrm{NaOH})$

\section{Hasil Pengujian XRF}

Pengujian XRF bertujuan untuk melihat komposisi kimia yang terkandung didalam zeolit dengan menggunakan metode spektrometri. Tabel menunjukkan hasil pengujian XRF masingmasing zeolit yang telah teraktivasi.

Tabel 1. Komposisi zeolit alam hasil pengujian XRF

\begin{tabular}{|c|c|c|c|c|c|c|c|c|c|}
\hline \multirow{2}{*}{$\begin{array}{c}\text { Zeolit Alam } \\
\text { setelah aktivasi }\end{array}$} & \multirow{2}{*}{$\begin{array}{c}\text { Konsentrasi } \\
\text { (M) }\end{array}$} & \multicolumn{8}{|c|}{ Jenis Mineral (\%) } \\
\hline & & $\mathrm{SiO}_{2}$ & $\mathbf{A l}_{2} \mathbf{O}_{3}$ & MgO & $\mathbf{P}_{2} \mathbf{O}_{5}$ & $\mathbf{K}_{2} \mathbf{O}$ & $\mathrm{CaO}$ & $\mathrm{TiO}_{2}$ & $\mathrm{Fe}_{2} \mathrm{O}_{3}$ \\
\hline $\mathrm{HCl}$ & 0.5 & 75.297 & 10.959 & 0.337 & 0.875 & 3.770 & 4.130 & 0.524 & 3.762 \\
\hline $\mathrm{HCl}$ & - & 75.475 & 11.029 & 0.270 & 0.874 & 3.486 & 4.336 & 0.460 & 3.397 \\
\hline $\mathrm{HCl}$ & 1.5 & 74.737 & 11.010 & 0.323 & 0.871 & 4.124 & 4.181 & 0.521 & 3.892 \\
\hline $\mathrm{HCl}$ & 2 & 75.917 & 11.327 & 0.411 & 0.775 & 3.475 & 3.743 & 0.502 & 3.568 \\
\hline $\mathrm{HCl}$ & 2.5 & 75.628 & 11.124 & 0.336 & 0.827 & 3.520 & 3.975 & 0.503 & 3.590 \\
\hline $\mathrm{NaOH}$ & 0.5 & 72.410 & 10.884 & 0.392 & 0.919 & 4.364 & 5.423 & 0.570 & 4.633 \\
\hline $\mathrm{NaOH}$ & 1 & 72.682 & 11.079 & 0.385 & 0.914 & 4.112 & 5.274 & 0.571 & 4.554 \\
\hline $\mathrm{NaOH}$ & 1.5 & 72.334 & 11.229 & 0.406 & 0.927 & 4.118 & 5.294 & 0.589 & 4.660 \\
\hline $\mathrm{NaOH}$ & 2 & 72.523 & 11.324 & 0.384 & 0.910 & 4.226 & 5.186 & 0.557 & 4.498 \\
\hline $\mathrm{NaOH}$ & 2.5 & 72.159 & 11.416 & 0.366 & 0.952 & 4.021 & 5.451 & 0.590 & 4.618 \\
\hline
\end{tabular}

Adanya penambahan larutan asam klorida $(\mathrm{HCl})$ kedalam zeolit alam bertujuan untuk melarutkan dan menghilangkan oksida-oksida logam yang menutupi permukaan zeolit dan terjerap didalamnya sehingga mengakibatkan permukaan bidang kontak lebih besar dan lebih porous. Sedangkan penambahan larutan basa natrium hidroksida $(\mathrm{NaOH})$ mengakibatkan pembentukan senyawa silikat dan menyebabkan permukaan zeolit berubah menjadi lebih negatif (Wang, et al., 2012). Aktivasi yang dilakukan secara kimiawi dengan asam atau basa bertujuan untuk membersihkan pori, membuang senyawa pengotor, dan mengatur kembali tata letak atom yang dipertukarkan. Tabel 1 menunjukkan, senyawa silika $\left(\mathrm{SiO}_{2}\right)$ dengan perlakuan asam $(\mathrm{HCl})$ berada dikisaran $75-76 \%$ sedangkan dengan perlakuan basa $(\mathrm{NaOH})$ berada dikisaran $72-73 \%$. Proses perlakuan asam pada zeolit alam menyebabkan terjadinya 
penurunan kandungan Ca dan Mg pada zeolit. Perlakuan dengan asam terhadap zeolit juga terbukti akan menyebabkan zeolit menjadi lebih hidrofobsehingga daya adsorpsinya terhadap air akan berkurang (Sumin, et al., 2009). Sedangkan aktivasi dengan basa menggunakan larutan $\mathrm{NaOH}$, penurunan rasio Si/Al akan terjadi pada aktivasi dengan $\mathrm{pH}$ tinggi. Dari proses aktivasi zeolit alam baik secara asam maupun basa, diperoleh hasil bahwa zeolit yang diaktivasi dengan basa akan menjadi lebih polar dibandingkan dengan zeolit yang diaktivasi dengan basa (Jozefaciuk dan Bowanko., 2002).

Aktivasi secara kimia dengan perlakuan asam bertujuan agar terjadi proses dealuminasi sehingga daya adsorpsi zeolit terhadap air berkurang karena bersifat hidrofobik (Sumin, et al., 2009). Dealuminasi dan dekationisasi ini terjadi karena $\mathrm{HCl}$ bereaksi dengan alumina membentuk $\mathrm{AlCl}_{3}$ dan $\mathrm{MCl}_{n}$. Tujuan dealuminasi adalah untuk mengoptimalkan kandungan aluminium pada zeolit sehingga zeolit memiliki selektivitas, mengontrol keasaman, dan menjadi lebih stabil pada temperature tinggi. Dealuminasi merupakan proses perusakan struktur kerangka zeolit dimana terjadi pemutusan Al dalam kerangka (Al framework) menjadi Al luar kerangka (Al non-framework) yang mengakibatkan rasio Si/Al semakin meningkat. Zeolit alam memiliki struktur yang tidak selalu sama tergantung kondisi pembentukannya di alam dan ini berbeda dengan zeolit sintesis dimana strukturnya dapat diprediksi dari senyawa penyusunnya. Proses aktivasi zeolit diperlukan untuk meningkatkan sifat khusus zeolit dan menghilangkan unsur pengotor yang terkandung didalam zeolit alam (Kurniasari, et al., 2011).

\section{KESIMPULAN}

Berdasarkan proses aktivasi kimia terhadap zeolit alam yang diaktivasi asam klorida $(\mathrm{HCl})$

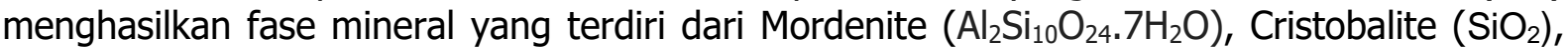
Trydimite $\left(\mathrm{SiO}_{2}\right)$, dan Moganite $\left(\mathrm{SiO}_{2}\right)$, dibandingkan dengan aktivasi menggunakan natrium hidroksida $(\mathrm{NaOH})$ menghasilkan fase mineral yang terdiri dari Mordenite $\left(\mathrm{Al}_{2} \mathrm{Si}_{10} \mathrm{O}_{24 .} .7 \mathrm{H}_{2} \mathrm{O}\right)$, Quartz $\left(\mathrm{SiO}_{2}\right)$, Cristobalite $\left(\mathrm{SiO}_{2}\right)$, dan Sanidine $\left(\mathrm{K}\left(\mathrm{AlSi}_{3} \mathrm{O}_{8}\right)\right)$. Mineral yang paling banyak terdapat di zeolit alam yaitu mordenite, yang cocok digunakan sebagai media adsorben. Selain itu, senyawa alumina sebesar $10-11 \%$ dan silika $72-76 \%$ merupakan komponen terbesar penyusun zeolit alam.

\section{UCAPAN TERIMAKASIH}

Penulis mengucapkan terimakasih pada Pimpinan Balai Penelitian Teknologi MineralLembaga Ilmu Pengetahuan Indonesia (BPTM-LIPI) yang telah memberikan izin tempat, waktu dan sarana prasarana kepada peneliti dalam melakukan penelitian sehingga berjalan dengan baik.

\section{DAFTAR PUSTAKA}

Al Muttaqii, M., Kurniawansyah, F., Prajitno, D.H., \&Roesyadi, A. 2019. Bio-Kerosene and biogasoil from coconut oils via hydrocracking process over Ni-Fe/HZSM-5 Catalyst, Bulletin Chemical Reaction Engineering \& Catalysis, 14 (2): 309-319

Ambarwati, S. 2005. Adsorpsi Pewarna Naftol dengan Zeolit sebagai Adsorben, Skripsi, Jurdik Kimia, FMIPA, UNY

Bekkum H., Flanigen, E.M., \& Jansen, J.C. 1991. Introduction to zeolite science and practice, Elsevier, Amsterdam

Demir, A., Gunay, A., \& Debik, E. 2002.Ammonium Removal from Aqueous Solution by Using Packed Bed Natural Zeolite, Water, 28: 3

Djaeni, M. Kurniasari L. Purbasari, A., \& Sasongko, S. 2010. Proceeding of the 1st International Conference on Materials Engineering., November 25- 26, Yogyakarta

Gaydardjief, S., Lambert, Ch., \& Frenay, J. 2001.Acta Metallurgica Slovaca, 4 (4) : 51-57 
Hamdan, H. 1992. Introduction to Zeolites: Synthesis, Characterization, and Modification, Universiti Teknologi Malaysia, Kualalumpur

Kurniasari, L. Djaeni, M., \&Purbasari, A. 2011. Aktivasi Zeolit Alam Sebagai Adsorben Pada Alat Pengering Bersuhu Rendah, Jurnal Reaktor, 13(3) : 178-184.

Mazloomi, F., Jalali, M. 2015. Ammonium Removal from Aqueous Solutions by Natural Iranian Zeolite in the Presence of Organic Acids, Cations and Anions, Journal of Environmental Chemical Engineering, $4: 240-249$

Sumin, L., Youguang, M.A., Chunying, Z., Shuhua, S.,\&Qing, H.E. 2009. The Effect of Hydrophobic Modification of Zeolites on $\mathrm{CO}_{2}$ Absorption Enhancement, Chinese Journal of Chemical Clays and Clay Mineral, 50(6): 771-783

Suriawan, M. C. Vahindra., \&T. G. T. Nindhia. 2010. Studi hubungan struktur mikro dan keaktifan zeolite alam akibat proses pengasaman, Jurnal IImiah Teknik Mesin Cakram, 4 (2): $129-131$

Tsitsishvili, G.V. 1992. Natural Zeolite, Ellis Horwood Ltd, Chichester

Wang, X. Ozdemir, O. Hampton, M. Nguyen, A. V. \&Duong, D. 2012.The effect of zeolite treatment by acids on sodium adsorption ratio of coal seam gas water, Water Research, 46(16) : 5247-5254 